\title{
Glaciers' wane not all down to humans
}

\section{Natural climate swings have had a major role in eroding Alpine ice.}

The Great Aletsch Glacier is ill. Over the course of the twentieth century, the largest Alpine glacier, in Valais, Switzerland, receded by more than two kilometres, and Switzerland's 1,500 smaller glaciers are not faring any better.

Is it all down to man-made global warming? Not according to a recent study, which finds that about half of the glacier loss in the Swiss Alps is due to natural climate variability ${ }^{1}-\mathrm{a}$ result likely to be true for glaciers around the world.

"This doesn't question the actuality, and the seriousness, of man-made climate change in any way," says Matthias Huss, a glaciologist at the University of Fribourg in Switzerland, who led the study. "But what we do see is that current glacier retreat might be equally due to natural climate variations as it is to anthropogenic greenhouse warming."

"This is the first detailed attribution of known climate forces on glacier behaviour," says Georg Kaser, a glaciologist at the University of Innsbruck in Austria, who was not involved in the study. "Given the importance of glaciers to local water supply, this is essential information."

Researchers have long suspected that glaciers respond sensitively to natural climate swings such as those caused by the rhythmic rise and fall of North Atlantic sea surface temperatures by up to $1^{\circ} \mathrm{C}$ roughly every 60 years. This Atlantic multidecadal oscillation (AMO), driven by changes in ocean circulation, is thought to affect phenomena including Atlantic hurricanes and rainfall in Europe.

In most places, historical records of glacier retreat and local climate are too sparse for researchers to separate the effect of this natural cycle from that of man-made warming. In the relatively well-monitored Swiss Alps, however, Huss and his team managed to gather some 10,000 in situ observations that had been made over the past 100 years, and constructed three-dimensional computer models of 30 glaciers. By comparing a time series of daily melt, snow accumulation and ice and snow volume readings of the glaciers with a widely used index of the AMO, they teased out the impact of natural climate variability. Although the mass balance of individual glaciers varied, the long-term overall trend followed the pulse of the AMO.
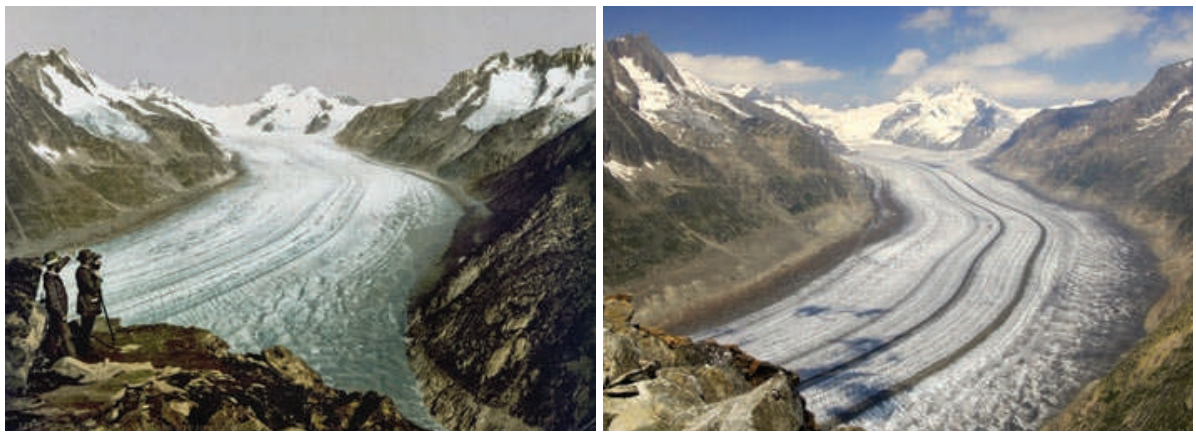

The Great Aletsch Glacier lost about $10 \mathrm{~km}^{3}$ of ice between 1890 (left) and 2005 (right).

Since 1910, the 30 glaciers have lost a total of 13 cubic kilometres of ice - about $50 \%$ of their former volume. Brief periods of mass gain during cool AMO phases in the 1910s and late 1970s were outweighed by rapid losses during warm phases in the 1940s and since 1980, when temperatures rose and more precipitation fell as rain than as snow. The scientists believe that these changes are due to the combined effects of the natural cycle and anthropogenic global warming, which now seems to have a greater role than early in the twentieth century.

\section{Subtle mix}

Natural climate variability is likely to have driven twentieth-century glacier shrinkage and thinning in other parts of the world, says Kaser. For example, his own research on the glaciers of Mount Kilimanjaro in Tanzania suggests that their dramatic recession is mainly due to multidecadal fluctuations in air moisture ${ }^{2}$.

"The widespread idea that glacier retreat is the sole consequence of increased air temperature is overly simplistic," he says. "Glaciologists have known for more than 50 years that glaciers are sensitive to a variety of climate variables, not all of which can be attributed to global warming."

Questions about the effect of global warming on glaciers hit the headlines earlier this year, after an error was found in the latest assessment report from the Intergovernmental Panel on Climate Change (IPCC), based in Geneva, Switzerland, which wrongly stated that most Himalayan glaciers could disappear by the year 2035 (ref. 3). The resulting furore put the IPCC's credibility under scrutiny, and has triggered an independent review by the
InterAcademy Council in Amsterdam, which represents 15 national academies of science.

But scientists don't expect the latest findings on Swiss glaciers to rekindle the controversy. "Without studies like this, climate science would actually be less credible than it is," says Martin Beniston, a regional climate modeller at the University of Geneva in Switzerland, who was not involved in the study. "Problems related to global warming are caused by a subtle mix of human activity and natural changes, and these new findings are a rare opportunity to illustrate this complexity in a comprehensible way. It is a question of scientific honesty to admit that not all the effects of climate change are solely the result of increased greenhouse gases."

Beniston adds that recognizing the role of natural climate shifts doesn't diminish the problem. "Even if greenhouse gases contribute just $50 \%$ to glacier retreat, this is anything but negligible." Although Himalayan glaciers may not be as vulnerable as the IPCC report originally suggested, the European Alps, where most glaciers are already in decline, could lose up to $90 \%$ of their glaciers by the end of the century, says Kaser.

The authors of the latest study cautiously suggest that a phase shift in the AMO might give a reprieve to Great Aletsch and other Alpine glaciers in the next decades, but Beniston is doubtful. "We may see a temporary slowdown, but I fear in the long run the still fairly modest greenhouse effect will outweigh any Atlantic relief."

Quirin Schiermeier

1. Huss, M., Hock, R., Bauder, A. \& Funk, M. Geophys. Res. Lett. 37, L10501 (2010)

2. Kaser, G., Hardy, D. R., Molg, T., Bradley, R. S. \& Hyera, T. M Int. J. Climatol. 24, 329-339 (2004).

3. Schiermeier, Q. Nature 463, 276-277 (2010). 